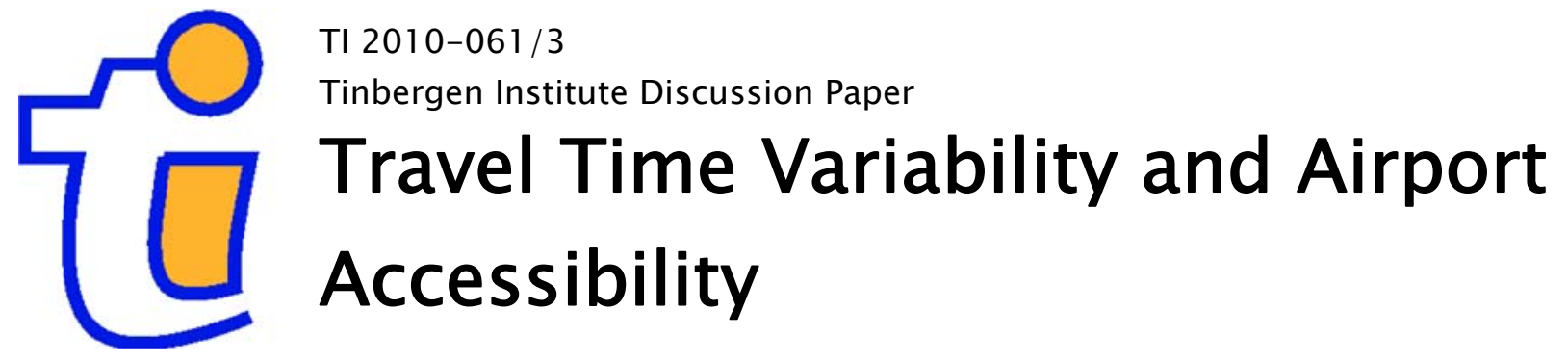

Paul Koster1,3

Eric Kroes 1,2

Erik T. Verhoefl,3

1 VU University Amsterdam;

2 Significance BV, The Hague;

3 Tinbergen Institute. 


\section{Tinbergen Institute}

The Tinbergen Institute is the institute for economic research of the Erasmus Universiteit Rotterdam, Universiteit van Amsterdam, and Vrije Universiteit Amsterdam.

Tinbergen Institute Amsterdam

Roetersstraat 31

1018 WB Amsterdam

The Netherlands

Tel.: +31(0)205513500

Fax: $+31(0) 205513555$

Tinbergen Institute Rotterdam

Burg. Oudlaan 50

3062 PA Rotterdam

The Netherlands

Tel.: + $31(0) 104088900$

Fax: $+31(0) 104089031$

Most TI discussion papers can be downloaded at http://www.tinbergen.nl. 


\title{
Travel time variability and airport accessibility
}

\author{
Paul Koster $^{1}$, Eric Kroes ${ }^{1,2}$, Erik Verhoef ${ }^{1}$ \\ 1 Department of Spatial Economics, VU University Amsterdam, The Netherlands \\ 2 Significance BV, The Hague, The Netherlands
}

May 2010

\begin{abstract}
This paper analyses the cost of access travel time variability for air travelers. Reliable access to airports is important since it is likely that the cost of missing a flight is high. First, the determinants of the preferred arrival times at airports are analyzed, including trip purpose, type of airport, flight characteristics, travel experience, type of check-in, need to check-in luggage. Second, the willingness to pay (WTP) for reduction in access travel time, early and late arrival time at the airport, and the probability to miss a flight is estimated using a stated choice experiment. The results indicate that the WTPs are relatively high, which is partially due to the low cost sensitivity of air travelers. Third, a model is developed to calculate the cost of variable travel times for air travelers going by car, taking into account travel time cost, scheduling cost and the cost of missing a flight. In this model, the value of reliability for air travelers is derived taking "anticipating departure time choice" into account. Results of the numerical exercise show that the cost of access travel time variability for business travelers are between 3-36\% of total access travel cost, and for non-business travelers between 3-30\%. These numbers depend strongly on the time of the day.
\end{abstract}

Keywords: value of reliability, scheduling, travel time variability, airport accessibility, airport choice

${ }^{1}$ Corresponding author: Paul Koster. Email: pkoster@feweb.vu.nl. Address: Faculty of Economics and Business Administration. De Boelelaan 1105, 1081HV Amsterdam, The Netherlands. 


\section{Introduction}

The accessibility of airports has been researched since several decades and it is an interesting topic for researchers, governments, airlines and airports. The work of Skinner (1976) and Harvey (1986) showed that the accessibility of airports is of vital importance for the choice of an airport by air travelers. Increasing the accessibility of an airport can therefore be one of the possible strategic actions of airports to improve their market position.

Accessibility can be measured in various ways. For example, distance can be used as a measure of accessibility. However, the distance between locations may not be a good proxy for accessibility if there is congestion on the road. Therefore access travel time is likely to be a better indicator. The analysis of Harvey (1986) already showed that travelers often choose an airport because it is nearby in terms of access travel time.

As indicated by Kouwenhoven (2008), a more general approach can be taken by using generalized access cost as an indicator for accessibility. In that case, all monetary cost for going to the airport such as parking cost and airport specific taxes are taken into account and non-monetary cost such as travel time can be multiplied by the willingness to pay (WTP) values of a traveler and added to monetary cost. Usually, this WTP is estimated using stated choice experiments (SCEs).

The WTP for a reduction in airport access travel time, or the value of access time (VOAT), has been frequently estimated in the literature. It has been found that the VOAT is considerably higher than the value of time for commuters. For example, Furuichi and Koppelman (1993) use RP data and find a value of $70 \$ / \mathrm{h}$ for business travelers and $41 \$ / \mathrm{h}$ for leisure travelers, although they add that there may be possible collinearity between travel time and travel cost and the estimations may be biased. Pels et al. (2003) find even higher values of $118 \$ / \mathrm{h}$ for non-business and $174 \$$ h for business travelers. Hess et al. (2007) find similar values as 
Furuichi and Koppelman for business and non-business travelers in a stated preference study. Hess and Polak (2005,2006), Dresner (2006) and Ishii et al. (2009) also show that there is significant heterogeneity in the WTP for a reduction in access travel time. Furthermore, Hess and Polak (2005) suggest that a possible reason for the high estimates of the VOAT could be that travelers see increasing travel times as an increase in risk to miss their flight.

The main contribution of this paper is that we include the cost of airport access travel time variability using a scheduling model. Earlier models take into account schedule delay at the destination (Lijesen, 2006; Hess et al. 2007), but ignore access travel time variability. The only study that incorporates the effects of access travel time variability that we are aware of is a revealed preference study by Tam et al. (2008). Tam et al. (2008) estimate the disutility of a safety margin that travelers apply when traveling to the airport. The safety margin in their study is defined as the difference between the preferred arrival time and the expected arrival time, and can be interpreted as the buffer that travelers take into account to cope with access travel time variability. They find that both business and non-business travelers are willing to pay money to decrease the safety margin by amounts between 1 and 1.3 times the WTP for reductions in travel time. We extend the paper of Tam et al. (2008) by explicitly explaining the determinants of the safety margin, using a scheduling model. In transport economics, the scheduling model has been frequently estimated for commuters (for overviews of empirical research see for example: Bates 2001; Brownstone and Small 2003; Tseng 2008; Li et al., 2010). It is an intuitive model, where travelers make a trade-off between the expected cost of being early and the expected cost of being late, and determine the optimal departure time from home. In this paper, the WTP values for reduction in schedule delay early, late and the probability to miss a flight are estimated. Second, a theoretical model for car travelers is developed, to analyze the cost of access travel time variability for car travelers taking into 
account anticipating departure time choice. This step is needed to connect the estimated WTP values to real travel time data. The resulting generalized cost can be implemented in accessibility models that analyze airport choice behavior of travelers (see, for example: Kouwenhoven 2008).

The main motivation for this paper is that the variability of travel time is important for air travelers, because the cost of missing a flight is expected to be high. Therefore travelers apply large buffers to be sure that they are on time. Using a departure time choice model it is possible to test the hypothesis of Hess and Polak $(2005,2006)$ that the high VOAT is the result of an increase in risk of missing a flight, because the risk to miss a flight is included explicitly in the model.

The setup of the paper is as follows. In section 2 the scheduling model for air travelers is introduced. This model differs from the standard models used for commuters in that travelers have large cost if they arrive later than their final check-in time. In the case of missing a flight it is likely that there will be a large penalty in terms of cost. Section 3 analyzes the determinants of the preferred arrival time of airport travelers. This is necessary because the preferred arrival influences the cost of travel time variability. In Section 4 binary (mixed) logit models are estimated to derive the WTP values for reductions in travel time and travel time variability, using data from a SCE. In section 5 a model is developed to derive the generalized access cost for car travelers taking into account travel time variability and anticipating behavior. These include the cost of access travel time and access travel time variability. Section 5 establishes the connection between the estimated WTPs and the observed travel time data. We use a large dataset of travel times to apply the model, and to calculate the cost of access travel time variability. Section 6 concludes and discusses the results. 


\section{The scheduling model for air travelers}

\subsection{The basic model}

The scheduling model of Noland and Small (1995) has been widely accepted as the standard tool of analyzing the effects of travel time variability. The work of Noland and Small is based on earlier work of Vickrey (1969) and Small (1982). The central idea is that travelers make a trade-off between being early and late, and evaluate earliness and lateness compared to their preferred arrival time $\left(t_{p a t}\right)$. In this paper, the model is extended to account for the specific concerns of air travelers. Notably, the departure time $\left(t_{h}\right)$ choice of air travelers is expected to strongly depend on the probability of missing a flight, and the corresponding expected cost.

Fig. 1 illustrates the assumed structure of the deterministic access cost function of an air traveler.

\section{Fig. 1 Deterministic access cost function of an air traveler}

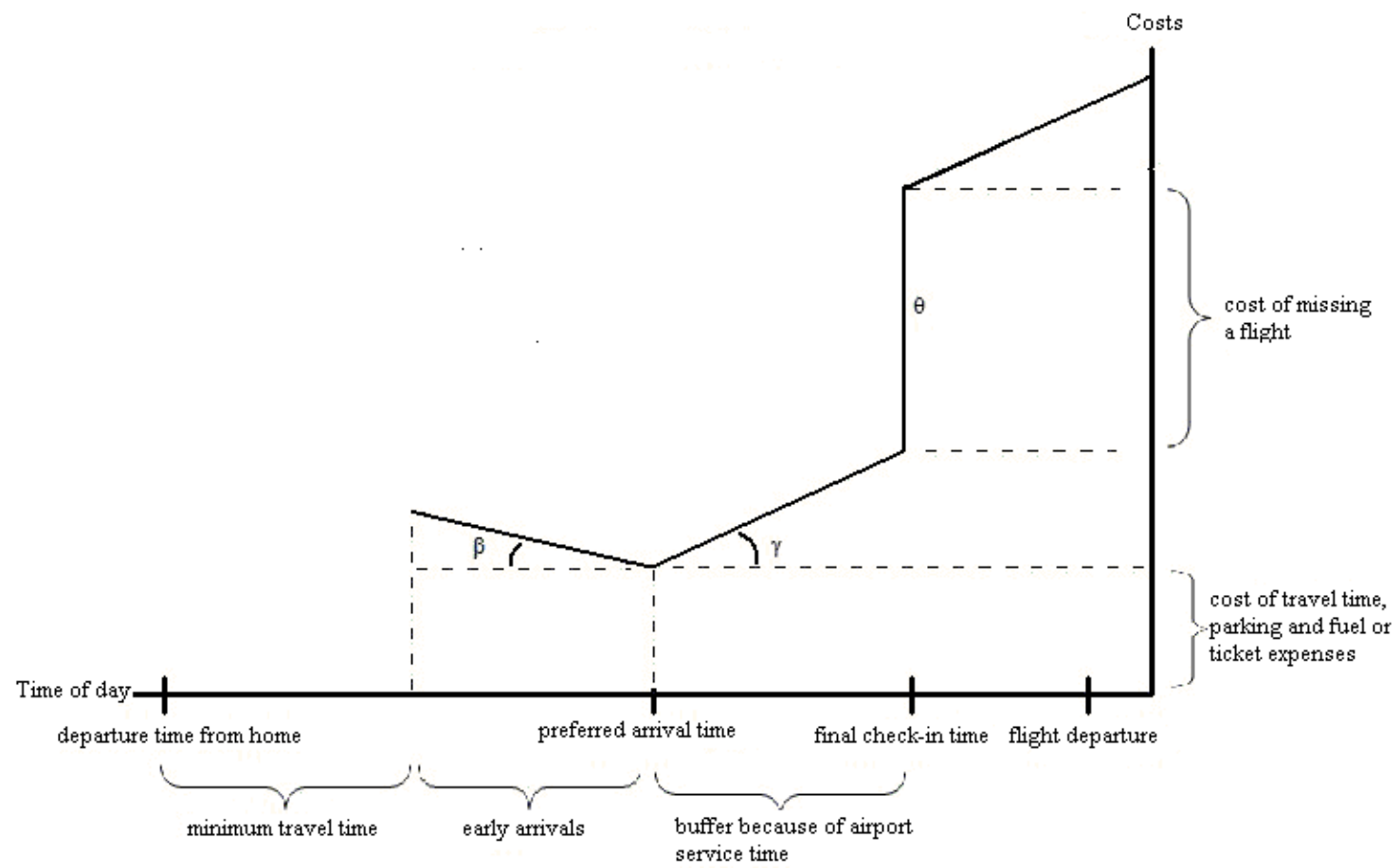


The x-axis of Fig. 1 indicates the time of day, and the y-axis indicate the cost. Suppose an air traveler has a certain flight departure time with a corresponding final check-in time. When a traveler is later than this final check-in time, he will miss his flight. The corresponding cost are likely to be high, and this is the reason why travelers may apply large buffers when going to the airport. In Fig 1, $\beta$ is the shadow cost of being early and $\gamma$ is the shadow cost of being late, both per unit of time and both relative to some most desired arrival time. The parameter $\theta$ is the discrete cost of missing a flight, which covers the cost for waiting, rebooking and other inconveniences. The schedule delay late refers to the valuation of excess time that can be spent at the airport whereas the schedule delay early captures the disutility of too much time spent at the airport.

When leaving from home, an air traveler first estimates what the in-airport service time and variability will be. The airport service time is defined as the time for checking in, going through the passport control, walking to the gate, boarding and security. Based on this subjective belief the traveler determines his preferred arrival time $t_{p a t}$. Longer perceived inairport service times will therefore result in an earlier $t_{p a t}$ (for a given scheduled flight departure time). The $t_{p a t}$ used in this paper is defined as the time a traveler wants to arrive at the airport when access travel time is not variable. This definition is crucial, since it enables us to separate the behavioral response to airport service time variability and access travel time variability. In section 3 the determinants of the $t_{p a t}$ are analyzed.

A late arrival is defined as being later than the $t_{p a t}$. It is likely that being late has some disutility since there will be extra stress, and therefore travelers are willing to pay money to reduce lateness. Being early also causes disutility, because of extra waiting time at the airport. The expected cost of a traveler depends on these parameters and the arrival time distribution, and are given by the cost function of Equation 1 . 
$E(C)=\alpha \cdot E(T)+\beta \cdot E(S D E)+\gamma \cdot E(S D L)+\theta \cdot P M F+Z$

$E(C)=$ expected access travel costs

$E(T)=$ expected travel time

$E(S D E)=$ expected schedule delay early

$E(S D L)=$ expected schedule delay late

$P M F=$ probability of missing the flight

$Z=$ other time of day independent expenses, such as parking costs

In Equation $1, \alpha$ is the value of airport access time $(V O A T), \beta$ is the value of schedule delay early (VSDE), $\gamma$ is the value of schedule delay late (VSDL) and $\theta$ the value of the probability to miss a flight $(V O P M F)$. The expected travel cost depend on the departure time from home since the schedule delay components and the probability to miss a flight are affected by the choice of departure time. Denoting the departure time from home as $t_{h}$ and the travel time as $T$, the schedule delay early $(S D E)$ is given by $\operatorname{Max}\left(0, t_{p a t}\left(t_{h}+T\right)\right)$ and the schedule delay late $(S D L)$ by $\operatorname{Max}\left(0, t_{h}+T-t_{p a t}\right)$. The corresponding expected values can be found by taking the expected value over the possible travel times $T$. The $E(S D E)$ increases and the $E(S D L)$ decreases if travelers depart earlier from home. Furthermore, the $P M F$ decreases if travelers depart earlier from home. Since travel times are stochastic, the corresponding arrival times will also be stochastic, and therefore the probability to miss a flight is included in the cost function rather than as a discrete penalty if the flight is missed. The probability to miss a flight depends both on the preferred arrival time and the departure time from home. In section 4 the WTP values will be estimated and in the next section the determinants of the preferred arrival time will be analyzed. 


\section{Determinants of the preferred arrival time}

\subsection{Descriptive statistics of the survey.}

An internet survey was held among Dutch air travelers to collect the data that are necessary for the analysis of the access cost function. A total of 971 completed surveys were collected with 345 reporting about a business trip and 626 reporting about a non-business trip. In the survey, information was asked about the latest trip to the airport. This information was used to customize the survey and the stated choice experiment. It was found that $1.5 \%$ of the air travelers ( $0.52 \%$ of all flights) had actually missed a flight during the last year, due to delays during their access trip. The summary statistics are given in Table 1.

\section{Table 1}

Summary results of the survey

\begin{tabular}{|l|r|r|}
\hline & non-business & business \\
\hline access mode & & \\
\hline car driver & $39,6 \%$ & $38,6 \%$ \\
car passenger ${ }^{2}$ & $25,4 \%$ & $21,4 \%$ \\
taxi & $8,9 \%$ & $7,0 \%$ \\
train & $20,1 \%$ & $30,1 \%$ \\
other & $5,9 \%$ & $2,9 \%$ \\
total & $100,0 \%$ & $100,0 \%$ \\
\hline characteristics of the last & & \\
trip & & \\
\hline average travel time & & \\
(minutes) & 82 & 79 \\
average \# of flights per & & \\
year & 2,66 & 5,84 \\
average duration of the trip & 12 days & 7 days \\
\hline airport chosen & & \\
\hline Schiphol Airport & $73,5 \%$ & $79,7 \%$ \\
small Dutch airports & $8,8 \%$ & $5,5 \%$ \\
Belgian Airports & $5,8 \%$ & $7,0 \%$ \\
German Airports & $11,3 \%$ & $6,1 \%$ \\
other & $0,8 \%$ & $1,7 \%$ \\
total & $100,0 \%$ & $100,0 \%$ \\
\hline
\end{tabular}

\footnotetext{
${ }^{2}$ If travelers do not travel alone, on average there are 3 people in the car.
} 
It is noteworthy that the modal share is quite similar for business and non-business travelers, except that business travelers take more often the train. This high share of train as an access mode is mainly caused by the fact that Schiphol Airport is very well connected by train and most travelers in the survey use Schiphol Airport as their departure airport. The mean average travel time, -defined as the average travel time from the location of departure to the check in counter at the airport-, is somewhat longer for non-business trips than of business travelers. The average number of flights for business travelers is more than twice that for non-business travelers. Finally, one can see that non-business travelers are traveling less often via Schiphol Airport and more often from German airports. Fig. 2 depicts the spatial distribution of the departure place of the respondents, based on 4-digit zipcode levels. There are more departures in the western part of The Netherlands, not in the least place because more people live and work there. For $86 \%$ of the business travelers the departure place is their home location. For non-business travelers this is true in $92 \%$ of the cases. This information is relevant for the analysis of airport choice, since residential locations are usually available in standard statistics while the work location is often unknown. 
Fig. 2 Spatial distribution of the departure place for business and non-business (personal) trips.
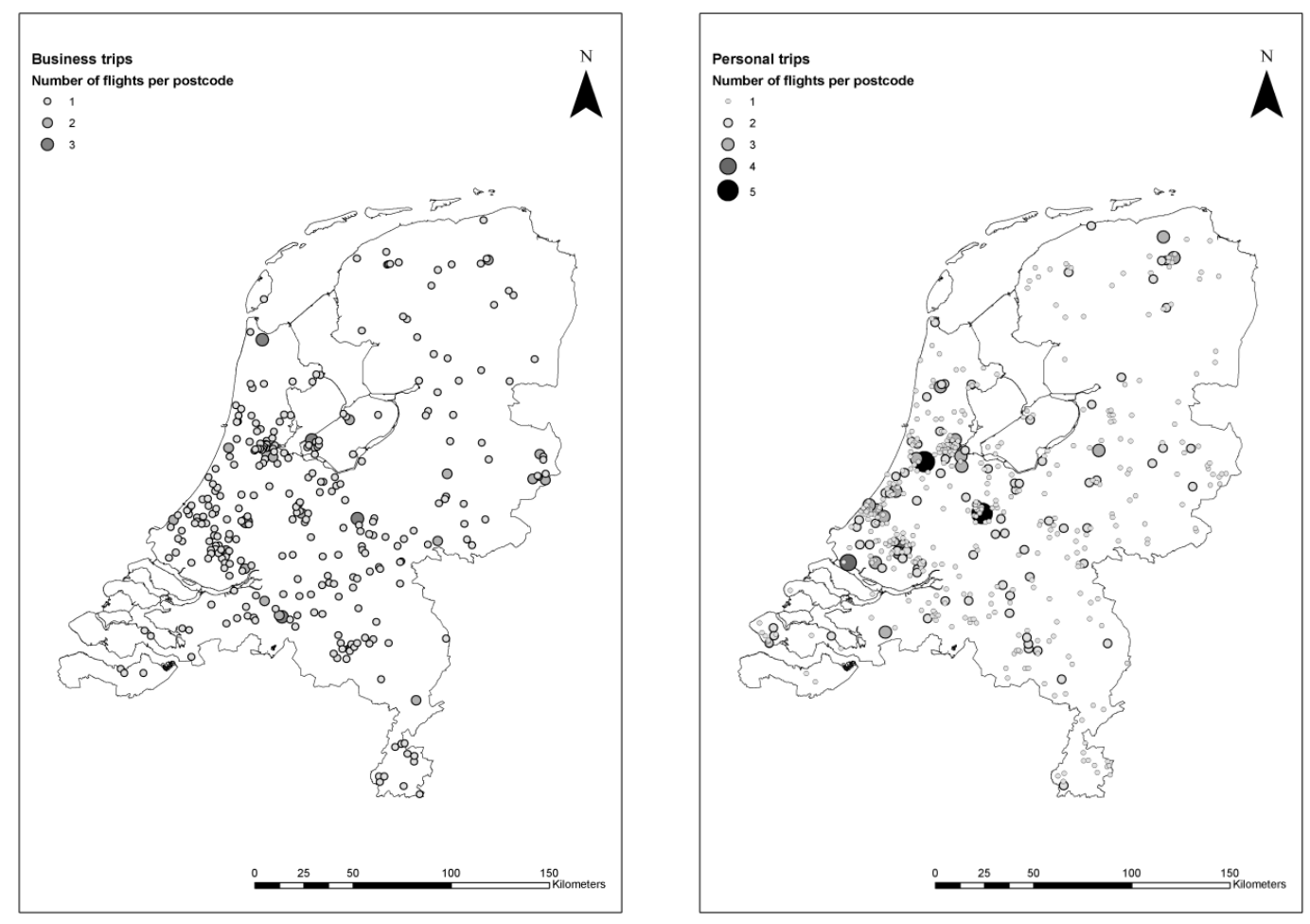

\subsection{Determinants of the preferred arrival time}

In this section the preferred arrival $\left(t_{p a t}\right)$ time at the airport is analyzed using basic regression analysis. We define $T_{\text {airport }}$ as the dependent variable in the regression, which is the scheduled flight departure time minus the preferred arrival time at the airport, so the number of minutes before the flight departure that a travelers prefers to arrive at the airport if there are no access travel time delays. The $t_{p a t}$ is an important determinant of the cost of variable airport access time as a larger value reduces the probability to miss a flight.

There are 930 observations included in the analysis. Travelers that arrive the previous day at the airport and sleep in a hotel are excluded from the analysis. Furthermore, travelers with a dependent variable lower or equal than 0 , or with very extreme values, are excluded from the analysis because they most likely made a mistake when filling in the questionnaire. 
In Table 2 the regression results are shown. $E(T)$ is the expected travel time of the traveler and FTT is the flight duration. For both variables the log transformation is used, because it is expected that the effect on the dependent variable is diminishing. Furthermore, variables for type of traveler, type of airport, type of check-in and time of the day are included. Also type of access mode was included, but this variable appears to be non-significant.

\section{Table 2}

Dependent variable: $T_{\text {airport }}$ (minutes)

\begin{tabular}{|l|cc|}
\hline Explanatory variables & Coefficient & t-value \\
\hline Constant (min) & $49.4^{* * *}$ & 5.01 \\
LN[E(T)] (min) & $3.5^{*}$ & 1.73 \\
LN[FTT] (hours) & $16.7^{* * *}$ & 9.43 \\
Business (dummy) & $-11.5^{* * *}$ & -3.66 \\
Retired (dummy) & $9.3^{* *}$ & 1.99 \\
5-10 flights per year (dummy) & $-10.0^{* * *}$ & -2.17 \\
More than 10 flights per year (dummy) & $-20.0^{* * *}$ & -3.34 \\
Check in luggage (dummy) & $15.9^{* * *}$ & -3.34 \\
Check in online (dummy) & $-9.5^{* * *}$ & -3.31 \\
Airport large (dummy) & $21.5^{* * *}$ & 5.36 \\
Airport mid (dummy) & $11.2^{* * *}$ & 1.86 \\
Flight departure between 0:00 and 7:00 (dummy) & $-11.8^{* * *}$ & -2.71 \\
\hline Adjusted R ${ }^{2}$ & 0.28 & \\
Number of observations & 930 & \\
\hline Notes: The size of airport is based & & \\
\hline
\end{tabular}

Notes: The size of airports is based on yearly number of passengers. Airport large are: Schiphol Airport and Frankfurt Airport. Airport mid are Airport Dusseldorf and Airport Brussels. Significance is indicated by ***, ** and * referring to significance at the $99 \%, 95 \%$ and $90 \%$ level, respectively.

The results show that longer expected travel times and longer flight travel times result in a larger $T_{\text {airport }}$. Furthermore, business travelers prefer to arrive later than non-business travelers. Travelers who are retired prefer to arrive earlier, likely because of less scheduling constraints and possibly because they move less quickly in the airport. 
Experience plays an important role. Travelers that fly between 5 and 10 times per year prefer to arrive on average 10 minutes later than travelers with less experience, and travelers that fly more than 10 times per year prefer to arrive on average 20 minutes later. This result indicates for example that uncertainty about in airport service times decreases, or risk avoiding reduces, when a traveler is more experienced. An experienced traveler has probably a better perception of the real in-airport service time than a non-experienced traveler, and possibly also of the possibilities to limit consequences of a late arrival at the airport.

If a traveler needs to check in luggage he prefers to arrive approximately 15 minutes earlier. If a traveler checks in online he prefers to arrive 10 minutes later. A good guess for the average perceived expected check-in time is therefore 25 minutes.

The type of airport influences the decision on the $t_{p a t}$. The larger the airport, the earlier the $t_{p a t}$ of travelers. The reason for this result is presumably that large airports are more crowded, or have longer walking times to the gate. If the flight departure time is early in the morning or during the night, travelers prefer to arrive later. This could be due to the fact that airports are less crowded during this time of day, possibly combined with a high shadow cost of disrupting sleep.

\section{Stated choice models}

A stated choice experiment (SCE) was developed to estimate the WTP values that the air travelers use in the cost function of Equation 1. An example of a choice question is given in

Fig. 3. The experiment is unlabeled, and respondents are asked to take their latest trip in mind when answering the questions. A 'none' option was not included to avoid that respondents would choose it simply because they do not want to put effort in making a choice. 


\section{Fig. 3 Example of a stated choice question.}

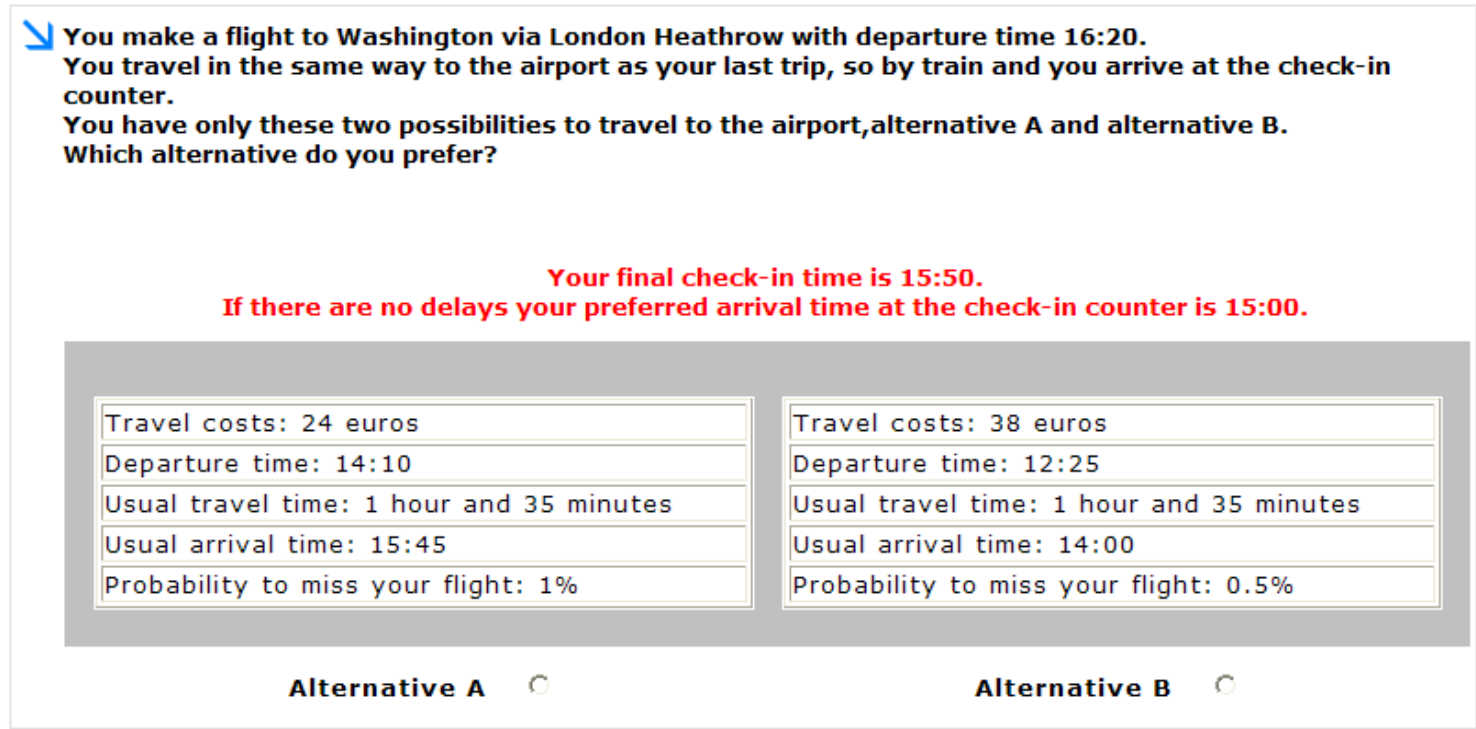

Above each choice question the circumstances of the trip are specified, based on earlier questions about the latest trip of the respondent. The trip destination, flight departure time, access mode and final destination are provided. If respondents travel by car, the parking cost is also provided. Above the choice question the final check-in time and the preferred arrival time of the respondent are shown. Before the experiment, it was explained that if travelers arrive before the final check-in time they will always catch their flight, so that the experiment controls for queuing at the check-in counters.

The first attribute of an alternative is the monetary travel cost which is based on the reference travel time of the respondent. The second and the third attribute are the departure time from home and the usual travel time. The usual arrival time is defined by these two attributes.

Finally, the probability of missing a flight is given as a percentage. Within a choice, the latest arrival will have a higher probability of missing a flight, because from the pilot study it was found that respondents find it very unrealistic and confusing when a later arrival would result 
in a lower probability of missing a flight. Respondents could ask additional explanation about percentages if they did not understand what percentages are. Only $6 \%$ of the respondents asked for additional explanation, and only 1 respondent did not understand what a percentage is after the explanation. ${ }^{3}$ It was explained that if a travelers arrives too late, he arrives 15 minutes after the final check-in time. Table 3 summarizes the possible attribute levels.

\section{Table 3}

Design attributes

\begin{tabular}{|l|l|l|}
\hline Design Attribute & Levels $^{4}$ & Remarks \\
\hline Cost & $0.15,0.2,0.25,0.3,0.4,0.45$ & $\begin{array}{l}\text { multiplied with reference travel time in minutes to obtain cost in } \\
\text { euros }\end{array}$ \\
\hline Travel time & $-15 \%,-5 \%, 0 \%, 10 \%, 20 \%$ & deviation from reference travel time \\
\hline Arrival & $5,10,35,50,90,110,120,170$ & minutes before final check-in time \\
\hline Probability to miss the flight & $0,0.5 \%, 1 \%, 1.5 \%, 2 \%, 3 \%$ & \\
\hline
\end{tabular}

The possible arrival times are based on the observed arrivals in a pilot study. In the choice experiment every respondent received 10 choices with 2 alternatives. The design has 13 blocks and is almost balanced for every respondent, meaning that every respondent received the attribute levels of Table 3, three or four times in the choice experiment.

After the experiment, some additional questions were asked about how the choices were made. Some respondents (5\%) are dropped from the analysis of the choice responses, either because they made mistakes in the questions about the reference trip or they indicated that they chose randomly between the alternatives. Almost $70 \%$ of the respondents indicated that they find the trade-offs realistic, which suggests that the attributes may indeed capture the most important aspects of the airport access utility function.

\subsection{Econometric setup}

For the estimation of the model a slightly generalized version of the mixed logit is used. The basic mixed logit model is not capable of capturing scale heterogeneity. Recently, Fiebig et al.

\footnotetext{
${ }^{3}$ However, this respondent is included in the analysis because it is unknown if the perception is also biased in a revealed preference situation.

${ }^{4}$ If taxi is the access mode the levels of the cost attribute is 0.3 higher.
} 
(2009) showed that scale heterogeneity might be an issue, although the results of Green and Hensher (2010) suggest that it not need be of major importance for estimating the mean WTP values. In the notation we follow Fiebig et al. (2009) who define the utility of person $n$ for alternative $j$ for choice $t$ as: ${ }^{5}$

$U_{n j t}=\sigma_{n} \cdot\left(\boldsymbol{\beta}+\eta_{n}\right) \cdot x_{n j t}+\varepsilon_{n j t}$

In equation 2 the vector $\boldsymbol{\beta}$ is homogeneous over the population while $\eta_{n}$ captures the individual specific component of the marginal utility. The parameter $\sigma_{n}$ captures the scale which is different over individuals. When $\eta_{n}=0$ and $\sigma_{n}=1$ the model reduces to a standard binary logit model with a scale parameter set to 1 (Fiebig et al. 2009). In the estimation we use a lognormal distribution for the scale, so $\sigma_{n}$ is defined by:

$\sigma_{n}=\exp (z)$, where $z \sim N\left(\lambda_{0}, \lambda_{1}\right)$

To estimate the model we constrain $\lambda_{0}=0$, because the standard deviation of the scale can be estimated but the mean is not identified. If $\lambda_{1}=0$, the formulation is exactly similar to the standard mixed logit model where the scale is usually normalized to 1 . The deterministic part of the utility is given by equation 4 (where the subscripts are omitted).

$V=\left(\beta_{C}+\beta_{D B C} \cdot D B C\right) \cdot C+\beta_{T} \cdot E(T)+\beta_{E S D E} \cdot E(S D E)+\beta_{E S D L} \cdot E(S D L)+\beta_{P M F} \cdot P M F$

In Equation (4), the $x$-variables are: travel cost $C$, expected travel time $E(T)$, expected schedule delay early $E(S D E)$ and the expected schedule delay late $E(S D L)$ The schedule delay variables capture the extra disutility of being early or late and do not capture the (dis)utility of having a shorter or longer trip. This (dis)utility is already captured by the travel time variable

\footnotetext{
${ }^{5}$ Fiebig et al. (2009) call this model GMNL-II. They also introduced GMNL-I where the scale only affects the vector $\boldsymbol{\beta}$, but not $\eta_{n}$.
} 
$T$. A separate cost coefficient for business travelers is estimated by including a dummy $D B C$, which is equal to 1 if the traveler is a business traveler and 0 otherwise. Finally, $P M F$ is the probability to miss a flight expressed as a percentage. The WTP values of equation 1 can be derived by taking the ratio of the marginal utilities. For example the value of access time is given by:

$V O A T=\frac{\beta_{T}}{\beta_{C}+\beta_{D B C} \cdot D B C}$

Similarly the VSDE, VSDL and VOPMF can be derived. In the estimated mixed models it is assumed that the cost coefficient is non-random, and that the other coefficients are normally distributed. Since the utility is linear in the parameters, WTP values can be derived by taking the ratio of the mean coefficient with the cost coefficient. The distribution of the scale cancels out for these WTP values. The models are estimated in Biogeme using maximum simulated likelihood (Bierlaire 2005, 2008; Train 2003). For the approximation of the integral 25000 Halton draws are used (Halton 1960).

\subsection{Estimation results}

The estimation results for the binary logit (BL), binary panel mixed logit (BPML) and the generalized binary panel mixed logit (GBPML) model are given in Table 4. The income level of a traveler does not affect the cost coefficient, and is therefore not included. The BPML model and the GBPML model give comparable results in terms of WTP values. Although the standard deviation of the scale parameter is significant and the loglikelihood improves, this does not seem to affect the mean and standard deviation parameters that much. The estimated standard deviations of the distributions do not decrease if scale heterogeneity is included. This is in line with the findings of Greene and Hensher (2010). 
Table 4

\begin{tabular}{|c|c|c|c|c|c|c|c|}
\hline & & \multicolumn{2}{|c|}{$\mathrm{BL}$} & \multicolumn{2}{|c|}{ BPML } & \multicolumn{2}{|c|}{ GBPML } \\
\hline Variable description & Symbol & Coefficient & t-value & Coefficient & $\overline{\mathrm{t} \text {-value }}$ & Coefficient & t-value \\
\hline mean cost coefficient & $\mu_{\mathrm{C}}$ & $-0.02 * *$ & -9.24 & $-0.04 * *$ & -7.67 & $-0.04 * *$ & -7.91 \\
\hline dummy business $*$ cost & $\mathrm{DBC}$ & $0.01 * *$ & 3.45 & $0.02 * *$ & 2.64 & $0.02 * *$ & 2.85 \\
\hline mean travel time coefficient & $\mu_{\mathrm{E}(\mathrm{T})}$ & $-1.09 * *$ & -9.67 & $-1.41 * *$ & -8.96 & $-1.44 * *$ & -9.04 \\
\hline mean expected schedule delay early coefficient & $\mu_{\mathrm{E}(\mathrm{SDE})}$ & $-0.69 * *$ & -22.02 & $-1.19 * *$ & -15.57 & $-1.32 * *$ & -14.25 \\
\hline mean expected schedule delay late coefficient & $\mu_{\mathrm{E}(\mathrm{SDL})}$ & $-1.22 * *$ & -26.93 & $-2.53 * *$ & -14.44 & $-2.59 * *$ & -12.56 \\
\hline mean probability to miss a flight coefficient & $\mu_{\mathrm{PMF}}$ & $-0.38 * *$ & -15.15 & $-0.55^{* *}$ & -11.94 & $-0.54 * *$ & -11.80 \\
\hline Standard deviations & Symbol & Coefficient & t-value & Coefficient & t-value & Coefficient & t-value \\
\hline standard deviation of travel time coefficient & $\sigma_{\mathrm{E}(\mathrm{T})}$ & - & - & $1.01 * *$ & 4.90 & $0.98 * *$ & 3.03 \\
\hline standard deviation expected schedule delay early coefficient & $\sigma_{\mathrm{E}(\mathrm{SDE})}$ & - & - & $-1.10 * *$ & -13.22 & $-1.31 * *$ & -13.01 \\
\hline standard deviation expected schedule delay late coefficient & $\sigma_{\mathrm{E}(\mathrm{SDL})}$ & - & - & $1.95 * *$ & 11.83 & $2.08 * *$ & 9.18 \\
\hline standard deviation probability to miss a flight coefficient & $\sigma_{\mathrm{PMF}}$ & - & - & $0.30 * *$ & 3.96 & $0.19 * *$ & 2.17 \\
\hline Scale & Symbol & Coefficient & t-value & Coefficient & t-value & Coefficient & t-value \\
\hline mean scale parameter & $\lambda_{0}$ & \multicolumn{2}{|c|}{--fixed-- } & \multicolumn{2}{|c|}{--fixed-- } & \multicolumn{2}{|c|}{--fixed-- } \\
\hline standard deviation of scale parameter & $\lambda_{1}$ & - & - & - & - & $0.33^{* *}$ & -3.10 \\
\hline Mean WTP values business & Symbol & \multicolumn{2}{|c|}{ mean } & \multicolumn{2}{|c|}{ mean } & \multicolumn{2}{|c|}{ mean } \\
\hline Value of access time (€/hour) & VOAT & \multicolumn{2}{|c|}{90.08} & \multicolumn{2}{|c|}{69.80} & \multicolumn{2}{|c|}{71.29} \\
\hline Value of schedule delay early ( $€$ /hour) & VSDE & \multicolumn{2}{|c|}{56.94} & \multicolumn{2}{|c|}{58.91} & \multicolumn{2}{|c|}{65.35} \\
\hline Value of schedule delay late (€/hour) & VSDL & \multicolumn{2}{|c|}{100.83} & \multicolumn{2}{|c|}{125.25} & \multicolumn{2}{|c|}{128.22} \\
\hline Value of the probability to miss a flight (€/\%) & VOPMF & \multicolumn{2}{|c|}{31.49} & \multicolumn{2}{|c|}{26.98} & \multicolumn{2}{|c|}{26.68} \\
\hline Mean WTP values non-business & Symbol & \multicolumn{2}{|c|}{ mean } & \multicolumn{2}{|c|}{ mean } & \multicolumn{2}{|c|}{ mean } \\
\hline Value of access time (€/hour) & VOAT & \multicolumn{2}{|c|}{45.80} & \multicolumn{2}{|c|}{36.91} & \multicolumn{2}{|c|}{35.82} \\
\hline Value of schedule delay early ( $€$ /hour) & VSDE & \multicolumn{2}{|c|}{28.95} & \multicolumn{2}{|c|}{31.15} & \multicolumn{2}{|c|}{32.84} \\
\hline Value of schedule delay late ( $€$ /hour) & VSDL & 51.2 & & 66. & & 64. & \\
\hline Value of the probability to miss a flight (€/\%) & VOPMF & 16.0 & & 14. & & 13. & \\
\hline Model characteristics & & & & & & & \\
\hline Loglikelihood & & -5187 & & -458 & & -457 & \\
\hline Pseudo-R ${ }^{2}$ & & 0.18 & & 0.2 & & 0.2 & \\
\hline Number of Observations & & 916 & & 916 & & 91 & \\
\hline Number of Halton draws & & - & & 250 & & 250 & \\
\hline
\end{tabular}

Note: ** indicates significance at the $95 \%$ level. The $\mathrm{t}$-values reported are robust $\mathrm{t}$-values.

Controlling for unobserved heterogeneity in the marginal utilities is important. The model

improvement is significant, and the mean VOAT and VSDL do change with a considerable amount. The resulting mean VOAT of the models are in line with earlier estimations in the literature. The estimated values are lower than the values found by Pels (2003) and comparable to the values found by Furuichi and Koppelman (1993) and Hess and Polak (2006). From additional questions in the survey about which factors travelers find important 
in the choice experiment, it was found that the high values of the WTPs are mainly the result of a low sensitivity to travel cost. The reason for this may be that travelers do not travel very often to the airport and therefore the cost for this trip are less important compared to the case of commuting, where the trip is made several times per week. Another issue might be that business travelers often receive cost compensation for their trip and therefore are less sensitive to travel cost.

For business and non-business travelers it was found that the typical pattern $V S D E<V O A T<V S D L$ appears. The ratio between the VOAT and $V S D E$ is close to 1 , and therefore higher than for commuters (Small 1982). Travelers are sensitive for reductions in the probability to miss their flight. The estimated WTP for a reduction in this probability is around $13 € / \%$ for non-business travelers and $27 € / \%$ for business travelers. If utility is linear in the probability to miss a flight, the cost of missing a flight for sure are around $€ 1341$ and $€$ 2668 respectively, which is higher than the average reported ticket price in our sample. This may be because of the extra disutility of rebooking flights, rescheduling appointments, loss of holidays and stress. ${ }^{6}$

\section{Calculation of the cost of airport access travel time variability for car users}

In this section the model is developed to calculate the cost of airport access travel time variability for car travelers. This is a crucial step in the analysis, because the connection is made between the estimated WTP values of the previous section and the observed travel time distribution taking into account anticipating behavior. It is assumed travelers optimize their departure time from home according to this travel time distribution and the mean estimated

\footnotetext{
${ }^{6}$ The linearity assumption has been tested by estimating a model with dummies for each level of the probability to miss a flight. The utility appears to be almost linear for both business and non-business travelers for values of the probability to miss a flight between 0 and $3 \%$. We also tested specifications with a lognormal cost coefficient and correlated distributions, but these models are not reported because they did not give stable results for the correlation parameters even for a high number of draws.
} 
WTPs of section 4. Furthermore it is assumed that the behavior of air travelers does not significantly change the behavior of other travelers because air travelers are only a very small fraction of the total traffic. Therefore the travel time distribution is assumed to be exogenous and it does not change if a traveler chooses his departure time.

One might well argue that $t_{p a t}$ is also a choice variable in the model because it depends on the WTP values as well. For example, travelers with a higher VOPMF are likely to have an earlier preferred arrival time. We control for the in-airport service time variability by assuming that $t_{\text {pat }}$ is fully explained by the regression results of section 3. Given their preferred arrival time travelers then choose their optimal departure time from home. This enables us to derive the expected scheduling cost due to access travel time variability, without knowing the distribution of the in-airport service time for which there is no data available.

The difference between the final check-in time and the preferred arrival time is denoted by $T_{\text {airport }}$. Since the final check-in time is usually fixed (around 45 minutes before the flight departure time) for an airport, the regression results of section 3 can be used to obtain empirical values for $T_{\text {airport }}$.

The results for the optimal cost with optimized departure time, as given by Noland and Small (1995) and Fosgerau and Karlström (2010) cannot be used in our case, since there is a kink after the $t_{p a t}$ as shown in Fig. 1. Define the headstart $H$ as $t_{p a t}-t_{h}$. A traveler faces a time-of-day dependent cumulative distribution of travel times, $F(T ; H)$ and corresponding probability density function $f(T ; H)$ with mean $\mu[H]$ and standard deviation $\sigma[H]$. The expected travel time for an air traveler is given by Equation 6, and is simply the time-of-day dependent mean travel time.

$E(T ; H)=\int T \cdot f(T ; H) \mathrm{d} T=\mu[H]$ 
The expected schedule delay early is given by Equation 7 by integration over all possible early arrivals. The integral starts at $T=0$ and ends at $T=H$, because then a travelers arrives exactly on time and the schedule delay early will be 0 .

$E(S D E ; H)=\int_{0}^{H}(H-T) \cdot f(T ; H) d T$

Similarly, the expected schedule delay late can be derived by integrating from $T=H$, where the schedule delay late is 0 , to the final check-in time $H+T_{\text {airport }}$, since it was assumed that all other schedule disutility, after the flight is missed, will be captured by the discrete variable $\theta$.

$E(S D L ; H)=\int_{H}^{H+T_{\text {airport }}}(T-H) \cdot f(T ; H) d T$

The probability of missing a flight $(P M F)$ for a given departure time and a given scheduled flight time depends on the variable $T_{\text {airport }} P M F$ can be written as:

$\operatorname{PMF}(H)=\int_{H+T_{\text {airport }}}^{\infty} f(T ; H) d T$

In Equation 9 the integral starts at the delay when the flight will be missed $\left(T=H+T_{\text {airport }}\right)$.

For all delays higher than this delay, travelers will miss their flight. The probability to miss a flight for a given $H$ is decreasing in $T_{\text {airport }}$. The optimization problem is given in Equation 10, where Equations 6-9 are multiplied with the corresponding WTP values that were estimated in section 4 .

$\min _{H} E(C)=\alpha \cdot E(T)+\beta \cdot E(S D E)+\gamma \cdot E(S D L)+\theta \cdot P M F$

The decision of the traveler is to determine the optimal $H$ which minimizes the expected travel cost based on the travel time distribution and his WTP values. There is no closed-form solution for this minimization problem. Therefore we empirically illustrate the model by 
taking a typical business and a non-business traveler going to Schiphol Airport, with mean WTP values as estimated in the GBPML model. For this analysis, loop detector data is used to construct time-of-day dependent travel time distributions where the origins are the highway ramps in The Netherlands and the destination is a highway ramp close to Schiphol Airport. In total 581 highway ramps are used in the analysis. The data entail observations for every 15 minute time-of-day interval. For each highway ramp, the data is interpolated to obtain 1minute interval data and is fitted with a kernel smooth density function because travel time distributions vary strongly over time-of-day ${ }^{7}$. In figure 4 we report the average percentage over all highway ramps of the cost of travel time variability in the total expected travel cost.

Fig. 4: Average percentage of the cost of access travel time variability in total access travel cost as a function of time-of-day for air passengers departing from Schiphol Airport using car as an access mode.

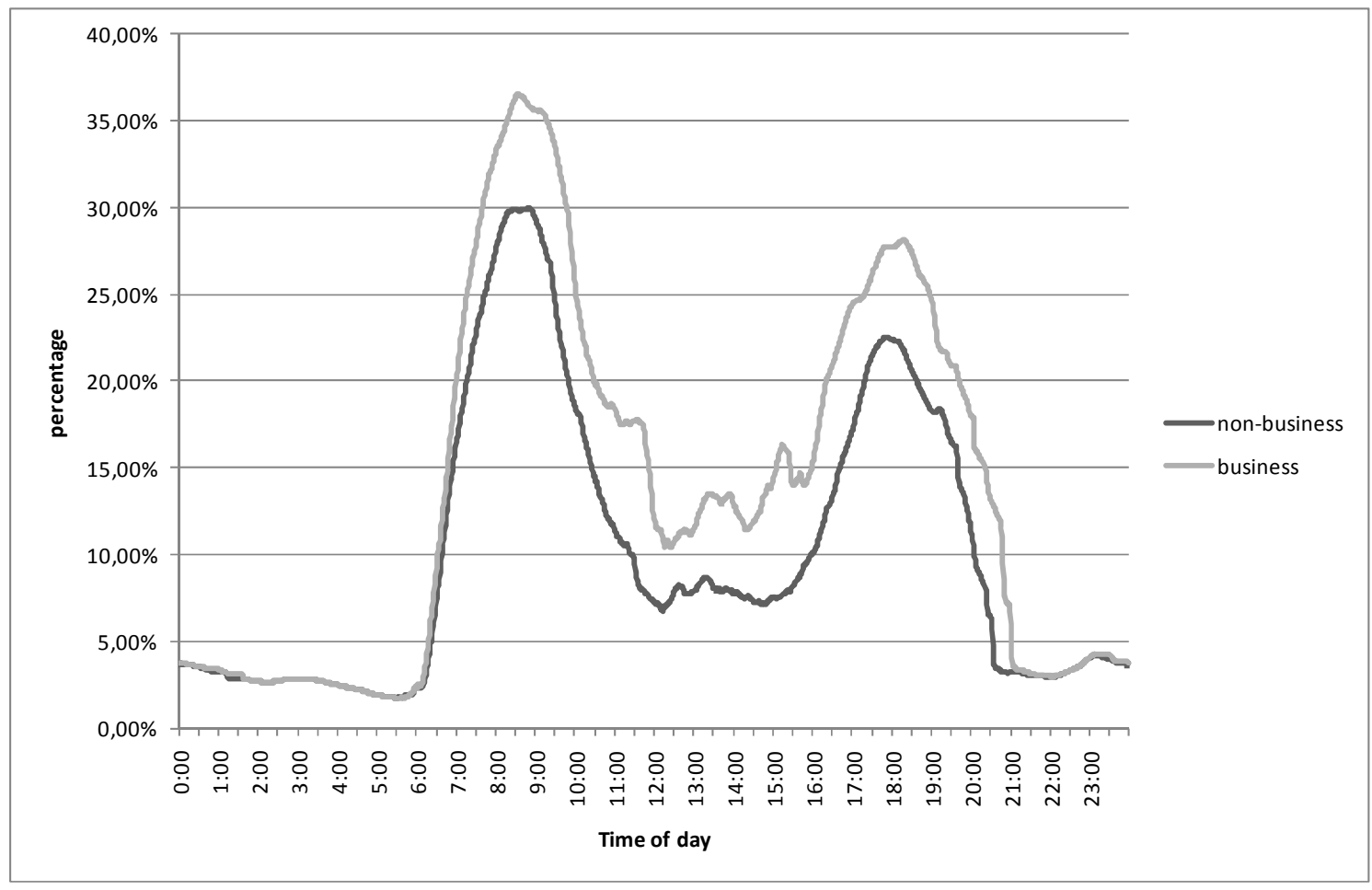

\footnotetext{
${ }^{7}$ For each time period, we use an optimal bandwidth for a normal kernel and use 100 equally spaced points. All programming has been done in Matlab 7.6.0.
} 
The results in figure 4 can be used as a rule of thumb to calculate the generalized access cost which serves as an input for airport choice models. We report the percentages as a function of time of day. For business travelers, the morning peak cost of travel time variability raise up to $36 \%$ and for the evening peak around $27 \%$. This number is somewhat higher than the number found by Fosgerau and Karlström (2010). During daytime this number is between 10 and $20 \%$, and during night time it drops to $3 \%$ because the variation in travel times is much lower. The results are intuitive, since the morning peak in The Netherlands has usually more severe congestion than the evening peak. Earlier work in the context of commuting already showed that the cost of travel time variability are strongly related to the cost of expected travel time, because the mean and the variance of travel time are strongly related in the presence of bottleneck congestion (Fosgerau 2009).

\section{Conclusions and discussion}

This paper analyzed the effect of airport access travel time variability on access travel cost. The binary logit and binary generalized mixed logit estimations show that, as expected, scheduling plays an important role in departure time decisions of travelers going to the airport. For both business and non-business travelers there is heterogeneity in the scheduling parameters, and controlling for such heterogeneity results in a lower mean value of access time. The mean value of access time was estimated on 35 euro for non-business travelers and 71 euro for business travelers and is in line with earlier findings in the literature (Furuichi and Koppelman 1993; Hess and Polak 2006).

Finally, a connection was made between the estimated shadow cost of scheduling and equilibrium cost taking into account anticipating departure time choice of air travelers. Using a large dataset of Dutch travel times we show that for business travelers the cost of variability are in between $3-36 \%$ depending on the time of day. For non-business travelers this number is 
in between 3-30\%. These numbers are somewhat higher than the values of Fosgerau and Karlström (2010) who analyzed the cost of travel time variability for commuters. The model that is developed in section 5 has some limitations. To calculate the generalized cost, it is assumed that air travelers have a perfect perception of the travel time distribution and that utility is linear in its arguments. For commuters perfect perception may be a realistic assumption because these travelers are usually experienced. But for air travelers it may well be that travelers do not know the travel time distribution, and therefore make larger perception errors. This may result in non-optimal behavior, and therefore the cost of variable travel times may be higher than estimated in the model of section 5 .

\section{Acknowledgements}

The authors like to thank Chris Jacobs of the SPINLAB (VU University Amsterdam) for GIS assistance. Furthermore, we like to thank Peter Schout of DVS (Directorate General for Public Works and Water Management) and Matthijs de Gier of TNS NIPO for collection and provision of the data. The usual disclaimer applies. The project "Reliable accessibility of airports" has been made possible with support of TRANSUMO (TRANsition SUstainable MObility). TRANSUMO is a Dutch platform for companies, governments and knowledge institutes that cooperate in the development of knowledge with regard to sustainable mobility.

\section{References}

Bates, J., Polak, J., Jones, P., Cook, A.J. 2001. 'The valuation of reliability for personal travel'. Transportation Research Part E 37 (2)-(3), 191-229.

Bierlaire, M. 2003. BIOGEME: A free package for the estimation of discrete choice models, Proceedings of the 3rd Swiss Transportation Research Conference, Ascona, Switzerland.

Bierlaire, M., 2008. An introduction to BIOGEME Version 1.7, biogeme.epfl.ch. 
Brownstone, D. and Small K.S. 2005. 'Valuing time and reliability: assessing the evidence from road pricing demonstrations', Transportation Research Part A, 39, 279-293.

Dresner, M., 2006. 'Leisure versus business passengers: Similarities, differences, and implications'. Journal of Air Transport Management 12 (1), 28-32.

Fiebig, D.G., Keane, M.P. Louviere, J., Wasi, N. 2009. ‘The Generalized Multinomial Logit Model: Accounting for Scale and Coefficient Heterogeneity'. Marketing Science. Articles in Advance pp.1-29.

Fosgerau, M., 2009. On the relation of mean and variance of delay in dynamic queues with random capacity and demand. Journal of Economic Dynamics and Control 34 (4), 598-603.

Fosgerau, M., Karlström, A., 2010. The value of reliability. Transportation Research B, 44 (1), 38-49.

Furuichi, M., Koppelman, F.S., 1993. An analysis of air travelers' departure airport and destination choice behavior. Transportation Research A 28 (3), 187-195.

Greene, W., Hensher, D. 2010. 'Does scale heterogeneity across individuals matter?

An empirical assessment of alternative logit models'. Transportation 37, 413-428.

Halton, J. 1960. On the efficiency of certain quasi-random sequences of points in evaluating multi-dimensional integrals. Numerische Mathematik 2, 84-90.

Harvey, G., 1986. Study of airport access mode choice. Journal of transportation Engineering $112(5), 525-545$.

Hess, S., Polak, J.W. 2005. Mixed logit modeling of airport choice in multi-airport regions. Journal of Air Transport Management 11 (2), 59-68. 
Hess, S., Polak, J.W. 2006. Airport, airline and access mode choice in the San Fransico Bay are. Papers in regional Science 85 (4), 543-567.

Hess, S., Adler, T., Polak, J.W. 2007. Modelling airport and airline choice behavior with the use of stated preference survey data. Transportation Research E (43), 221-233.

Ishii, J., Jun, S., Dender, van, K., 2009. Air travel choices in multi-airport markets. Journal of Urban Economics 65 (2), 216-227.

Kouwenhoven, M. 2008. The Role of Accessibility in Passengers' Choice of Airports, OECD Discussion Paper No. 2008-14, Paris.

Li, Z., Hensher, D.A., Rose, J. 2010. Willingness to pay for travel time reliability in passenger transport: A review and some new empirical evidence. Transportation Research E 46, 384403.

Lijesen, M. 2006. A mixed logit based valuation of frequency in civil aviation from SP-data. Transportation Research E 42 (2), 82-94.

Noland, R. B., Small, K. A. 1995. Travel-Time Uncertainty, Departure Time Choice, and the Cost of Morning Commutes, Transportation Research Record, 1493, 150-158.

Pels, E., Nijkamp, P., Rietveld, P. 2003. 'Access to and competition between airports: a case study for the San Fransisco Bay area'. Regional Studies 35 (1), 1-9.

Pels, E., 2003. Airport economics and policy. Efficiency, Competition and Interaction with Airlines. PhD Dissertation, VU University Amsterdam, Tinbergen Research Series No. 222. Skinner, R.E. 1976. Airport choice: an empirical study. Transportation Engineering Journal $102(4), 871-882$. 
Small, K.A. 1982. The scheduling of consumer activities: work trips. American Economic Review, 72, (3), 469-479.

Tam, M.L., Lam, H.K., Lo, H.P. 2008. Modeling air passenger travel behavior on airport ground access mode choices. Transportmetrica 4 (2), 135-153.

Tseng, Y.-Y., 2008. Valuation of Travel Time Reliability in Passenger Transport. PhD Thesis, VU University Amsterdam, Tinbergen Research Series No.439.

Train K 2003. Discrete choice methods with simulation. Cambridge University Press, Cambridge, MA

Vickrey, W.S., 1969. Congestion theory and transport investment. American Economic Review 59, 251-261. 